\title{
VARIABILIDADE GENÉTICA NA REGIÃO ITS DO rDNA DE ISOLADOS DE Trichoderma spp. (BIOCONTROLADOR) e Fusarium oxysporum f. sp. Chrysanthemi
}

\author{
Genetic variability in rDNA ITS region of Trichoderma spp. (biocontrole agent) and \\ Fusarium oxysporum f. sp. chrysanthemi isolates
}

\author{
Josiane Pacheco Menezes ${ }^{1}$, Manoeli Lupatini², Zaida Inês Antoniolli ${ }^{3}$ Elena Blume ${ }^{4}$, \\ Emanuele Junges ${ }^{5}$, Clarice G. Manzoni'
}

\begin{abstract}
RESUMO
A análise de características morfológicas e culturais podem não ser suficientes para uma caracterização precisa das espécies de Trichoderma e Fusarium. Objetivou-se, neste trabalho, caracterizar a região do Espaço Interno Transcrito (ITS) do rDNA dos isolados UFSMT15.1, UFSMT16 e UFSMT17 de Trichoderma spp. utilizados no biocontrole de Fusarium oxysporum f. sp. chrysanthemi (isolado) UFSMF6. A extração de DNA de cada isolado foi realizada a partir de micélio produzido em meio líquido Batata-Dextrose. As amostras de DNA genômico foram submetidas à Reação em Cadeia da Polimerase (PCR) com os oligonucleotídeos iniciadores universais ITS1 e ITS4 e o produto gerado foi sequenciado. Os fragmentos gerados pela amplificação da PCR foram tratados com as enzimas de restrição HaeIII, HinfI e MboI. As regiões ITS1, ITS2 e 5.8S do rDNA desses isolados fúngicos foram amplificadas com sucesso. A região ITS dos isolados UFSMT15.1, UFSMT16 e UFSMT17 de Trichoderma e o isolado UFSMF6 de Fusarium apresentaram uma banda simples com um fragmento de aproximadamente 600 pares de base (pb). As enzimas de restrição HaeIII, HinfI e MboI geraram polimorfismo de bandas entre os isolados. Com base nas análises da sequência de DNA, os isolados UFSMT15.1, UFSMT16, UFSMT17 e UFSMF6 apresentaram maior similaridade com as espécies Trichoderma koningiopsis, Hypocrea virens, Hypocrea lixii e Fusarium oxysporum, respectivamente.
\end{abstract}

Termos para indexação: Fungos de solo, caracterização molecular, sequências, endonucleases, análises de DNA.

\section{ABSTRACT}

The analysis of morphological and cultural characteristics may not enough for the characterization of the species of Trichoderma and Fusarium. The aim of this work was to characterize the Internal Transcribed Spacer (ITS) region of the rDNA of UFSMT15.1, UFSMT16 and UFSMT17 isolates of Trichoderma spp. used in the biocontrol of Fusarium oxysporum f. sp. chrysanthemi UFSMF6. DNA extraction of each isolate was accomplished starting from hyphae produced in liquid medium Potato-Dextrose-Agar. The samples of genomic DNA were submitted to the Polymerase Chain Reaction (PCR) with the primers ITS1 and ITS4, and the product was sequenced. The fragments generated from PCR amplification were digested with the restriction enzymes HaeIII, HinfI and MboI. The ITS region of the Trichoderma's isolates UFSMT15.1, UFSMT16 and UFSMT17 and the Fusarium UFSMF6 isolate showed a simple band with a fragment with 600 base pairs (bp) approximately. The restriction enzymes HaeIII, HinfI and MboI generated band polymorphism among the isolates. The isolates UFSMT15.1, UFSMT16, UFSMT17 and UFSMF6 showed high similarity whit Trichoderma koningiopsis, Hypocrea virens, Hypocrea lixii and Fusarium oxysporum species, respectively.

Index terms: Soilborne fungi, molecular characterization, sequences, endonucleases, DNA analysis.

(Recebido em 8 de setembro de 2008 e aprovado em 19 de março de 2009)

\section{INTRODUÇÃO}

O gênero Trichoderma possui espécies de fungos que são economicamente importantes principalmente pela sua capacidade de produzir enzimas, antibióticos e atuação no controle biológico. Algumas espécies têm sido relatadas como importantes na degradação de xenobióticos no solo (Kindermann et al., 1998), e também como agentes de biocontrole de fitopatógenos do solo, como T. harzianum,

\footnotetext{
${ }^{1}$ Colégio Técnico Industrial de Santa Maria - Universidade Federal de Santa Maria/UFSM - Av. Roraima n 1000, Camobi - Cx.P.221 - 97105-900 - Santa Maria,RS - josiflor@yahoo.com.br

2Universidade Federal de Santa Maria/UFSM - Departamento de Solos - Santa Maria, RS

${ }^{3}$ Universidade Federal de Santa Maria/UFSM - Departamento de Solos - Santa Maria, RS

${ }^{4}$ Universidade Federal de Santa Maria/UFSM - Departamento de Defesa Fitossanitária - Santa Maria, RS

${ }^{5}$ Universidade Federal de Santa Maria/UFSM - Departamento de Defesa Fitossanitária - Santa Maria, RS

${ }^{6}$ Universidade Federal de Pelotas/UFPel - Departamento de Fitossanidade - Pelotas, RS
} 
T. viride e T. hamatum (Arisan-Atac et al., 1995). Esses fungos também podem agir como agentes promotores de crescimento em plantas, na germinação de sementes e na produção de flores. Respostas à aplicação de Trichoderma spp. são caracterizadas por aumentos significativos na porcentagem de germinação, no peso seco e na altura de plantas (Melo, 1996).

A identificação de Trichoderma é, geralmente, baseada em características morfológicas, tais como forma, tamanho, cor e ornamentação dos conídios; presença e forma de ramificações; e formação de elongações (estéreis ou férteis) dos conidióforos (Rifai, 1969; Bisset, 1984). Entretanto, descrições das espécies são baseadas na análise de um número limitado de isolados, que apresentam alta similaridade, assim, muitas vezes a análise de características morfológicas e culturais são ineficientes para a caracterização das espécies de Trichoderma (Fujimori \& Okuda, 1994).

Fusarium é um dos gêneros de fungos com várias espécies capazes de causar doenças em plantas, como as podridões de raízes, caules e frutos, além das murchas vasculares. O gênero possui ampla distribuição geográfica, com ocorrência em todas as regiões do mundo (Poletto et al., 2006). Algumas espécies são particularmente comuns no solo, onde podem persistir sob a forma de clamidósporos ou como hifas, enquanto outras espécies produzem conídios disseminados pelo ar, colonizando normalmente ramos, folhas, inflorescências e frutos (Edel, 1997; Ventura, 1999). A identificação de Fusarium em espécies, formae speciales e raças é bastante trabalhosa e muitos parâmetros devem ser avaliados (Windels, 1991). Os métodos moleculares têm sido úteis para auxiliar na diferenciação desses níveis (Kistler et al., 1987).

A identidade dos seres vivos é determinada pela composição e sequência do material genético. O uso de técnicas moleculares, através da análise de DNA, possui a vantagem de ser um processo rápido e altamente sensível. Essas técnicas não estão sujeitas a variações fenotípicas, à ação do ambiente, ao estágio de desenvolvimento do fungo e a outros fatores que possam alterar a morfologia do organismo (Manso \& Tenente, 1984). A diferenciação genética entre populações de uma espécie constitui o primeiro estágio da divergência evolutiva. Essa diferenciação resulta, na maioria dos casos, da ação de diferentes ambientes a que cada população está sujeita sobre a variabilidade preexistente na espécie (Marques, 2003). As técnicas conhecidas de diagnóstico molecular fundamentam-se na análise direta ou indireta da composição ou na sequência dos ácidos nucléicos para identificação e caracterização de organismos (Marques et al., 2002).
Esses métodos moleculares baseados na análise do ácido desoxirribonucléico (ADN ou DNA) são ferramentas muito úteis nos estudos de filogenia de fungos e na diferenciação de espécies, formae speciales, raças e isolados (Kumarae \& Sousa, 2002), pois são capazes de determinar o polimorfismo existente entre as sequências de nucleotídeos dos organismos (Kistler et al., 1987). A análise macromolecular baseada nos ácidos nucléicos tem sido usada para diferenciar entre e dentro dos agregados de Trichoderma, podendo demonstrar a diversidade genética de isolados individuais (Hermosa et al., 2000).

Uma técnica muito utilizada para taxonomia de fungos é a amplificação da região ITS do rDNA por PCR. A região ITS está localizada entre os genes 18SrDNA e 28SrDNA e pode ser amplificada por oligonucleotídeos iniciadores específicos (Hillis \& Dixon, 1991). O ITS é dividido em ITS1, localizado entre os gens $18 \mathrm{~S}$ e o $5.8 \mathrm{~S}$, e o ITS2, que separa os genes 5.8S e 28S (Hillis \& Dixon, 1991; Schlotterer et al., 1994). Enquanto as regiões dos genes ribossomais são altamente conservadas dentro da espécie, as regiões dos espaçadores ITS, por evoluirem mais rapidamente, podem variar intraespecificamente na sequência de bases e no comprimento (Gerbi, 1985), sendo frequentemente usadas para taxonomia de espécies e gêneros (Schlotterer et al., 1994; Antoniolli et al., 2000; Gomes et al., 2002).

Objetivou-se, no presente trabalho determinar a variabilidade genética da região do ITS do rDNA e a diversidade de polimorfismo genético dos isolados UFSMT15.1, UFSMT16 e UFSMT17 de Trichoderma utilizados no biocontrole de Fusarium f. sp. chrysanthemi.

\section{MATERIAL E MÉTODOS}

Os isolados de Trichoderma (UFSMT15.1, UFSMT16 e UFSMT17) e $F$. oxysporum f. sp. chrysanthemi (UFSM F6) utilizados neste estudo foram obtidos a partir do teste de Confronto Direto (Bell et al., 1982). Esses, foram obtidos a partir de teste com 100 isolados de Trichoderma, dentre os quais selecionaram-se os três isolados mais eficientes no biocontrole do isolado de Fusarium (UFSMF6) (Menezes, 2007). Para a obtenção de micélio, os isolados foram multiplicados em meio de cultura líquido batata-dextrose (Dhingra \& Sinclair, 1995) por sete dias, a $25^{\circ} \mathrm{C}\left( \pm 2{ }^{\circ} \mathrm{C}\right)$ e fotoperíodo de $12 \mathrm{~h}$, em incubadora BOD (Nova técnica, NT 708-AT). O DNA dos isolados foi extraído do micélio conforme protocolo de Doyle \& Doyle (1990) e armazenadas a $-20^{\circ} \mathrm{C}$.

Para a caracterização taxonômica dos isolados de Trichoderma spp. e Fusarium, utilizaram-se os 
oligonucleotídeos iniciadores ITS1 (5'TTC CGT AGG TGA ACC TGC GG 3') e ITS4 (5' TCC TCC GCT TAT TGA TAT GC 3') (White et al., 1990; Hermosa et al., 2000; Kumarae \& Sousa, 2002). A reação totalizou $25 \mu \mathrm{L}$ contendo aproximadamente $30 \mathrm{ng}$ de DNA, tampão 10X, 2,5 $\mu \mathrm{M}$ de cada DNTP, $20 \mathrm{nM}$ de $\mathrm{MgCl}_{2}, 25$ ñmoles da cada um dos oligonucleotídeos iniciadores (Biogen), cinco unidades da enzima Taq polimerase e água ultrapura para completar o volume da reação. As reações foram realizadas em termociclador MJ Research, INC. PTC $-100^{\mathrm{MT}}$, sob as seguintes condições térmicas: $94^{\circ} \mathrm{C}$ por $2 \mathrm{~min}, 30$ ciclos de $94{ }^{\circ} \mathrm{C}$ por $45 \mathrm{~s}, 55^{\circ} \mathrm{C}$ por $30 \mathrm{~s}, 72^{\circ} \mathrm{C}$ por $35 \mathrm{~s} \mathrm{e} 72{ }^{\circ} \mathrm{C}$ por 10 min. Ao final da reação, o produto foi mantido a $-4{ }^{\circ} \mathrm{C}$. Um controle negativo sem DNA foi incluído nas amplificações do PCR. Os fragmentos amplificados e o controle foram separados por eletroforese em gel de agarose $1,2 \%$, em tampão TBE 1X, contendo brometo de etídio, visualizado sob luz ultravioleta e fotografado atravéz do sistema Canon Snot S2IS. A reação da PCR para o DNA de cada isolado foi realizada 10 vezes nas mesmas condições para obter a reprodutividade dos dados.

Os produtos da PCR foram tratados separadamente com as endonucleases HaeIII, Hinfl e MboI. A digestão foi realizada num total de $20 \mu \mathrm{L}$, a $37^{\circ} \mathrm{C}$, durante $12 \mathrm{~h}$. Em seguida, os fragmentos de restrição foram separados em gel de agarose a 1,2\%, em tampão TBE $1 \mathrm{X}$, a $60 \mathrm{mV}$ por cerca de $3 \mathrm{~h}$. Cada reação foi repetida duas vezes para cada isolado. Os géis foram visualizados e fotografados através do sistema Canon Snot S2IS.

Os produtos da PCR foram purificados com PEG $800013 \%$ e, nas reações de sequenciamento, utilizaram-se os oligonucleotídeos ITS1 e ITS4. Para as reações de sequenciamento, foi seguido o protocolo fornecido pelo fabricante. $\mathrm{O}$ sequenciamento foi realizado no sequenciador Mega BACE 500 (Amersham). Os fragmentos sequenciados foram analisados utilizando-se o programa BioEdit (Halli, 1999). Após, as sequências obtidas foram inseridas no GenBank, sediado no National Center for Biotechnology Information (NCBI) (http// 'WWW.ncbi.nlm.nih.gov) ('Altschul et al., 1997), onde receberam o código de acesso: EU545538 (F. oxysporum f. sp. chrysanthemi UFSMF6), EU545539 (Trichoderma UFSMT17), EU545540 (Trichoderma UFSMT16) e EU545541 (Trichoderma UFSMT15.1).

Para a construção da árvore filogenética, as sequências de nucleotídeos obtidas dos diferentes isolados foram submetidas ao alinhamento pelo programa Basic Local Alignment Search Tool (BLAST). As sequências do GenBank que apresentaram os dez maiores scores foram selecionadas para análise filogenética. As sequências de nucleotídeos foram alinhadas pelo programa ClustalW e a análise filogenética foi conduzida utilizando o método "Neighbour-joining", com 5000 replicatas pelo programa MEGA, versão 4 (Tamura et al., 2006). A similaridade das sequências de nucleotídeos entre os isolados foi calculada pelo programa DNASTAR (Lasergene, 1994).

\section{RESULTADOS E DISCUSSÃO}

O DNA dos isolados de Trichoderma e de Fusarium foram extraídos e amplificados eficientemente. O tamanho dos fragmentos amplificados foi de aproximadamente 600 pares de bases $(\mathrm{pb})$ para os três isolados de Trichoderma (Figura 1a) e para o isolado de Fusarium (Figura 2a). Os fragmentos amplificados visualizados na mesma posição no gel de agarose foram considerados de mesmo tamanho.

Não houve variação no comprimento das regiões ITS1, ITS2 e 5.8S entre os três isolados de Trichoderma. A região 5.8S apresentou tamanho de 158 nucleotídeos e similaridade de $100 \%$ para os três isolados. Essa similaridade também foi observada entre os três isolados estudados (Tabela 1) e os isolados obtidos do Genbank (Tabela 2) para a mesma região (Tabela 1). As regiões ITS1 e ITS2 dos diferentes isolados apresentaram diferenças na constituição nucleotídica (Tabela 1). Tais resultados corroboraram os trabalhos de Kistler et al. (1987) e Kumarae \& Sousa (2002), onde através de métodos moleculares de análise do DNA foi possível diferenciar espécies, uma vez que esses detectam o polimorfismo existente entre as sequências de nucleotídeos dos organismos.

Tabela 1 - Similaridade genética (\%) da região ITSr do DNA e ITS1 e ITS2 do rDNA entre os isolados Trichoderma UFSMT17 (A), Trichoderma UFSMT16(B), e Trichoderma UFSMT15.1 (C), baseado no método Wilbur-Lipman.

\begin{tabular}{cccccccccc}
\hline & \multicolumn{3}{c}{ ITS } & \multicolumn{3}{c}{ ITS1 } & \multicolumn{2}{c}{ ITS2 } \\
\hline Isolados & $\mathrm{A}$ & $\mathrm{B}$ & $\mathrm{C}$ & $\mathrm{A}$ & $\mathrm{B}$ & $\mathrm{C}$ & $\mathrm{A}$ & $\mathrm{B}$ & $\mathrm{C}$ \\
\hline $\mathrm{A}$ & 100 & 54,4 & 51,8 & 100 & 64,7 & 61,8 & 100 & 82,5 & 85,2 \\
B & & 100 & 94,6 & & 100 & 96,8 & & 100 & 88,1 \\
$\mathrm{C}$ & & & 100 & & & 100 & & 100 \\
\hline
\end{tabular}

Ciênc. agrotec., Lavras, v. 34, n. 1, p. 132-139, jan./fev., 2010 
O isolado $F$. oxysporum f. sp. chrysanthemi (UFSMF6) apresentou o mesmo comprimento da região 5.8S dos isolados de Trichoderma spp., porém não a mesma constituição nucleotídica. A similaridade entre as regiões 5.8S dos isolados de Trichoderma e do Fusarium (UFSMF6) foi de 98,1\%. Já a similaridade entre o isolado Fusarium (UFSMF6) estudado e os obtidos no Genbank foi de $100 \%$.

Os tamanhos de fragmentos gerados pelas endonucleases de restrição, aplicadas aos produtos de amplificação da PCR da região do ITS do rDNA não foram suficientes para a diferenciação dos três isolados de Trichoderma spp. (Figura 1b). A enzima HaeIII gerou pelo menos um fragmento no isolado UFSMT15.1, enquanto que nos isolados UFSMT16 e UFSMT17 a enzima gerou pelo menos três fragmentos, sendo dois fragmentos maiores que 200 pares de bases e um fragmento de $18 \mathrm{pb}$. A enzima HinfI cortou a fita do DNA dos três isolados em pelo menos três regiões, gerando dois fragmentos maiores, um ao redor de $300 \mathrm{pb}$ e outro ao redor de $200 \mathrm{pb}$. Os outros fragmentos gerados foram menores que $100 \mathrm{pb}$, ficando esses difusos no gel. A enzima $M b o I$ cortou várias vezes a sequência de nucleotídeos, gerando fragmentos de DNA menores de $200 \mathrm{pb}$. A banda difusa que aparece abaixo do nível de 200 $\mathrm{pb}$ do marcador corresponde a bandas que apresentam um comprimento médio de 150 bp. O produto de DNA da PCR também foi cortado em pedaços menores, que são perceptíveis apenas como arraste no gel (Figura 1b). Como o principal objetivo foi caracterizar os isolados de Trichoderma spp., não foram aplicadas endonucleases de restrição para o isolado $F$. oxysporum f. sp. chrysanthemi UFSMF6.

As sequências dos três isolados de Trichoderma spp., quando submetidas ao GenBank, apresentaram os maiores scores com as sequências apresentadas na Tabela 2 e Figura 3. $\mathrm{O}$ agrupamento por similaridade indica que o isolado UFSMT17 apresentou maior similaridade com a espécie Hypocrea lixii (fase sexual de Trichoderma sp.), o isolado UFSMT16 apresentou os maiores scores com a espécie Hypocrea virens e o isolado UFSMT15.1 apresentou maiores scores com a espécie $T$. koningiopsis. A conformação da árvore filogenética indica que não houve variações na região ITS entre isolados do mesmo gênero, demonstrando a necessidade da conciliação de características morfológicas e moleculares para a identificação de subespécies, raças ou formae speciales para esses organismos.

$\mathrm{O}$ isolado de $F$. oxysporum f. sp. chrysanthemi (UFSMF6) utilizado, quando submetido ao alinhamento pelo BLAST, apresentou homologia, isso é apresentou maior número de resíduos que pareiam com isolados da espécie F. oxysporum. A identificação de Fusarium em espécies é bastante trabalhosa, porém, neste trabalho e, de acordo com Kistler et al. (1987), os métodos moleculares empregados foram eficientes na identificação do isolado UFSMF6.

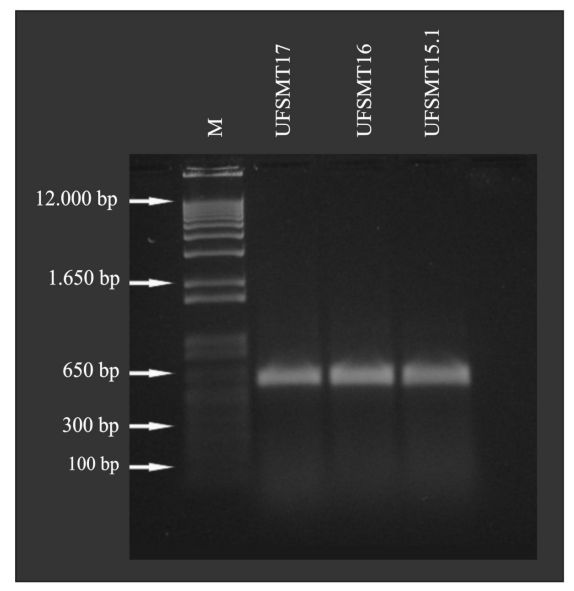

(a)

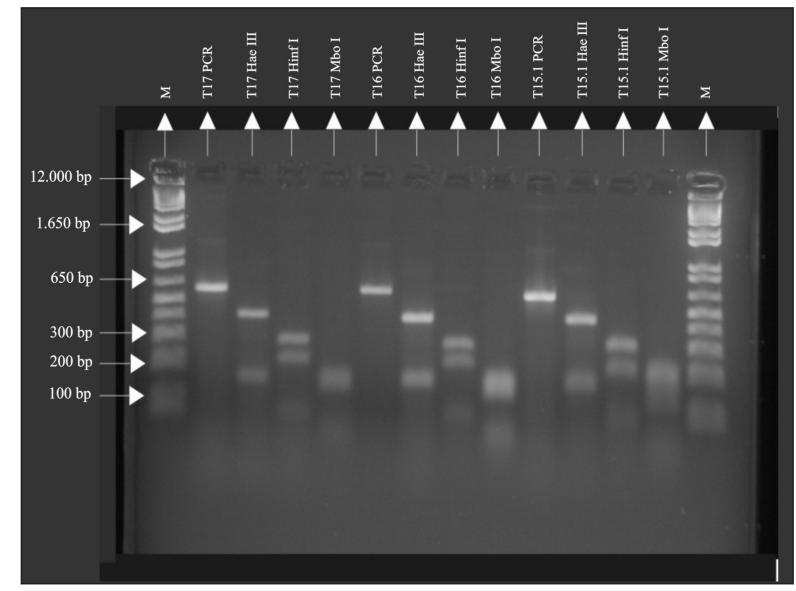

(b)

Figura 1 - (a) Produto de amplificação por PCR do DNA genômico em gel de agarose dos isolados UFSMT17, UFSMT16 e UFSMT15.1 de Trichoderma spp. usando os primers ITS1 e ITS4. M - Marcador molecular 1 Kb Plus DNA Ladder, Gibco. (b) Produto da amplificação por PCR de DNA e da digestão enzimática com HaeIII, HinfI e MboI dos isolados UFSMT17, UFSMT16 e UFSMT15.1 de Trichoderma. (pb) Pares de bases. 
Tabela 2 - Isolados de Trichoderma spp. e Fusarium spp. obtidos do GenBank usados para este estudo.

\begin{tabular}{|c|c|c|}
\hline Isolados $^{1}$ & Número de acesso $^{2}$ & Referência \\
\hline Hypocrea lixii strain FG68 & EU030373 & Wang \& Qian (2007) \\
\hline H. lixii isolate UOKT033 & EF442074 & Vahabi et al. (2007) \\
\hline H. lixii isolate UOKT023 & EF442079 & Vahabi et al. (2007) \\
\hline H. lixii isolate UOKT044 & EF442082 & Vahabi et al. (2007) \\
\hline H. lixii isolate & AM498496 & Hageskal (2007) \\
\hline H. Virens isolate J13/A8 & AF483585 & Thornton et al. (2002) \\
\hline H. Virens isolate J13/B7 & AF483586 & Thornton et al. (2002) \\
\hline H. Virens isolate UOKT079 & EF442078 & Vahabi et al. (2007) \\
\hline H. Virens isolate UOKT076 & EF442081 & Vahabi et al. (2007) \\
\hline H. Virens strain UNISS & EF596954 & Megheli et al. (2007) \\
\hline T. Koningiopsis strain GJS 04-376 & DQ323425 & Samuels et al. (2005) \\
\hline T. Koningiopsis strain GJS 04-378 & DQ323432 & Samuels et al. (2005) \\
\hline T. Koningiopsis strain GJS 04-373 & DQ323437 & Samuels et al. (2005) \\
\hline T. Koningiopsis & AB374281 & Miyazaki et al. (2008) \\
\hline T. Koningiopsis strain strain UNISS $17 b-15$ & EF488150 & Migueli et al. (2007) \\
\hline F. solani & AAM940071 & Gomez (2008) \\
\hline F. oxysporum & AF443071 & Quader \& Riley (2001) \\
\hline F. oxysporum strain F-T.1.7-030514-31 & EU364850 & Zheng et al. (2007) \\
\hline F. oxysporum strain F-T.1.7-040427-1 & EU364854 & Zheng et al. (2007) \\
\hline F. oxysporum strain PR5 & EU429440 & Gullino (2008) \\
\hline F. oxysporum strain F-H.6.5-030318-02 & EU364842 & Zheng et al. (2007) \\
\hline F. oxysporum f. sp. chrysanthemi UFSM F6 & EU545538 & Menezes et al. (2008) \\
\hline Trichoderma lixii UFSMT17 & EU545539 & Menezes et al. (2008) \\
\hline Trichoderma virens UFSM16 & EU545540 & Menezes et al. (2008) \\
\hline Trichoderma koningiopsis UFSMT15.1 & EU545541 & Menezes et al. (2008) \\
\hline
\end{tabular}

${ }^{1}$ Isolados e ${ }^{2}$ número de acesso dos mesmos no GenBank - NCBI.

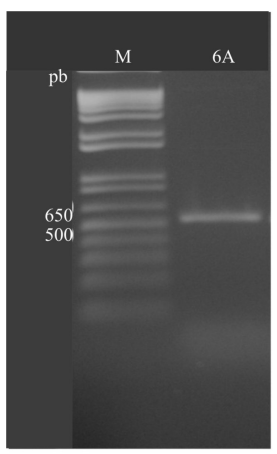

(a)

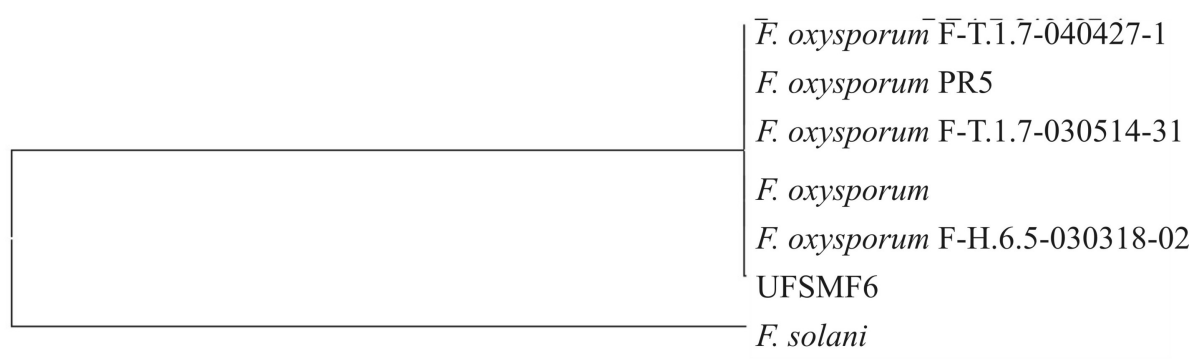

(b)

Figura 2 - (a) Produtos de amplificação por PCR do DNA genômico em gel de agarose do isolado de $F$. oxysporum f. sp. chrysanthemi UFSMF6 usando os primers ITS1 e ITS4. M - Marcador molecular 1 Kb Plus DNA Ladder, Gibco. (b) Dendograma filogenético baseado na análise "Neighbour-joining" da região ITSrDNA com base em 5000 réplicas de "bootstrap". O isolado F. solani foi utilizado como "outgroup". 


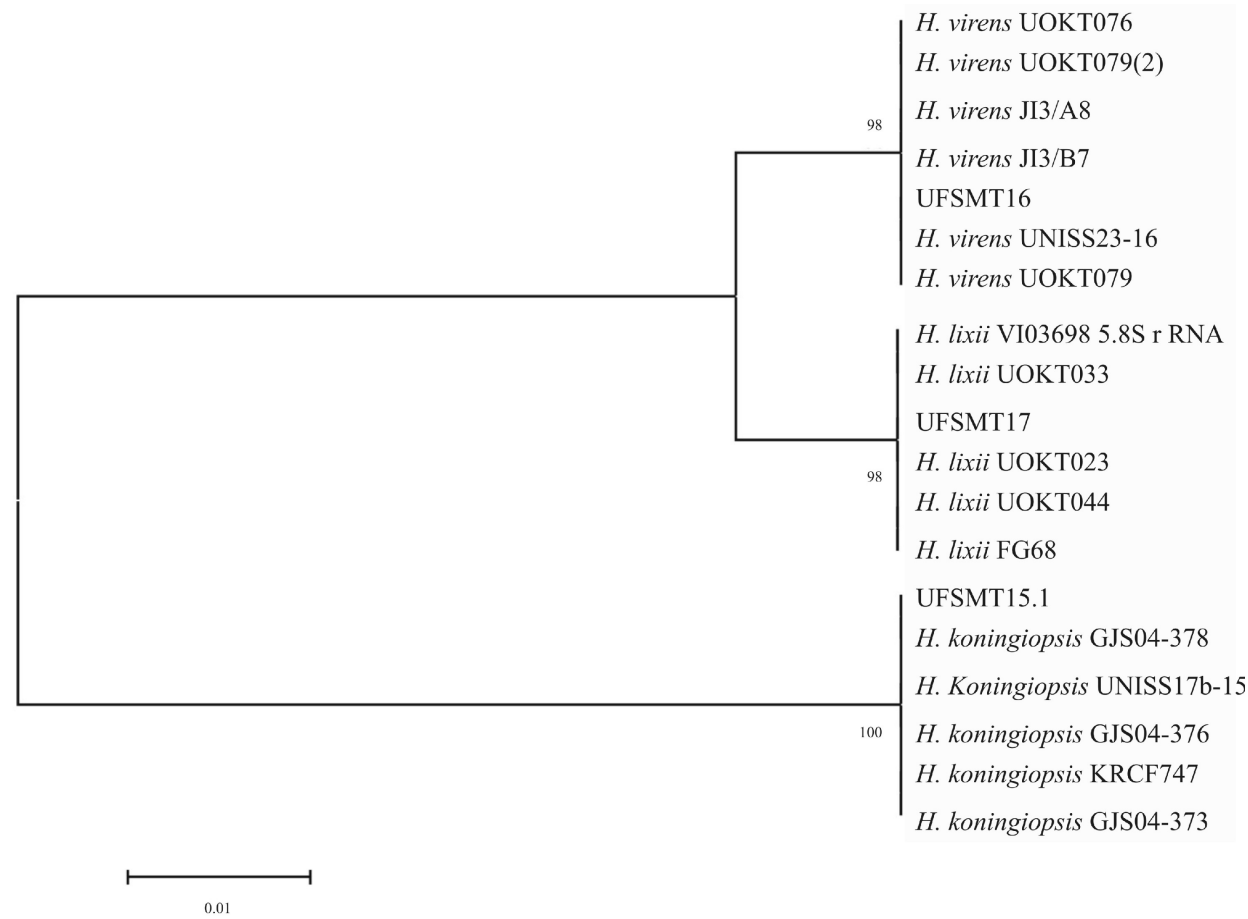

Figura 3 - Dendograma baseado na análise "Neighbour-joining" derivado das sequências das regiões ITSrDNA, com base em 5000 réplicas de "bootstrap", de isolados de Trichoderma UFSMT15.1, UFSMT16 e UFSM T17 e de sequências obtidas do GenBank de diferentes isolados de espécies de Trichoderma spp. O número nas ramificações representa o número de "bootstrap".

A taxonomia, a genética e a composição da população de Trichoderma spp. não são ainda bem compreendidas e, portanto, são necessários métodos mais precisos para diferenciar linhagens de diferentes espécies para propósito de patente ou determinação de variabilidade de linhagens em ecossistemas naturais (Peres \& Melo, 1995). Assim, os resultados sugerem que técnicas moleculares através do sequenciamento direto do produto do PCR-ITSrDNA combinado com características morfológicas são eficientes para a separação e identificação de espécies de Trichoderma e também de Fusarium, uma vez que a taxonomia somente pela morfologia pode não ser suficiente para a caracterização de espécies (Fujimori \& Okuda, 1994).

Portanto, os resultados obtidos reforçam a idéia de que a identificação de espécies baseada somente em características morfológicas e culturais tem limitações, uma vez que essas são influenciadas pelo ambiente, alterando o fenótipo de isolados fúngicos.

\section{CONCLUSÕES}

Os fragmentos gerados pelas enzimas de restrição usadas não foram suficientes para identificação ou separação dos isolados de Trichoderma, pois apenas demonstrou sensível diferença entre eles.
O sequenciamento de bases da região ITS foi um eficiente método para identificação e separação de isolados de Trichoderma e Fusarium.

\section{REFERÊNCIAS BIBLIOGRÁFICAS}

ALTSCHUL, S.F.; MADDEN, T.L.; SCHAFFON, A.A.; ZHANG, J.; ZHANG, Z.; MILLER, W.; LIPMAN, D.J. Gapped BLAST and PSI-BLAST: a new generation of protein data base search programs. Nucleic Acids Research, Bethesda, v.73, n.17, p.3389-3402, 1997.

ANTONIOLLI, Z.I.; SCHACHTMAN, D.; OPHELKELLER, D.; SMITH, S.E. Variation in ribosomal internal transcribed spacer sequences in Glomus mosseae and Gigaspora margarita spores from a permanent pasture. Mycological Research, Amsterdam, v.104, n.1, p.708-715, 2000.

ARISAN-ATAC, I.; HEIDENREICH, E.; KUBICEK, C.P. Randomly amplified polymorphic DNA fingerprinting identifies subgroups of Trichoderma viride and other Trichoderma sp. capable of chestnut blight biocontrol. FEMS Microbiology Letters, Delft, v.126, n.3, p.249-256, 1995. 
BELL, D.K.; WELLS, H.D.; MARKHAM, C.R. In vitro antagonism of Trichoderma species against six fungal plant pathogens.Phytopathology,Cornell,v.72, n.4, p.379-382, 1982

BISSET, J. A revision of the genus Trichoderma sp. Sect. Longibrachiatum sect. Canadian Journal of Botany, Morden, v.69, n.1, p.924-931, 1984.

DHINGRA, O.D.; SINCLAIR, J.B. Basic plant pathology methods. Florida: CRC, 1995. 434p.

DOYLE, J.J.; DOYLE, J.L. Isolation of plant DNA from fresh tissue. Focus, Ithaca, v.12, p.13-18, 1990.

EDEL, V.; STEINBERG, C.; GAUTHERON, N.; ALABOUVETTE, C. Populations of nonpathogenic Fusarium oxysporum associated with roots of four plant species compared to soilborne populations.

Phytopathology, Cornell, v.84, n.7, p.693-697, 1997.

FUJIMORI, F.; OKUDA, T. Application of the random amplified polymorphic DNA using the polymerase chain reaction for efficient elimination of duplicate strains in microbial screening fungi. The Journal of Antibiothics, Tokyo, v.47, n.2, p.173-182, 1994.

GERBI, S.A. Evolution of ribosomal DNA. In: MCINTYRE, R.E. Molecular evolutionary genetics. New York: Plenum, 1985. p.419-517.

GOMES, E.A.; KASUYA, M.C.M.; BARROS, E.G.; BORGES, A.C. Polymorphism in the internal transcribed spacer (ITS) of the ribosomal DNA of 26 isolates of ectomycorrhizal fungi. Genetics and Molecular Biology, São Paulo, v.25, n.4, p.477-483, 2002.

HALLI, T. BioEdit: a user-friendly biological sequence alignment editor and analysis program for Windows 95/ 98/NT. Nucleic Acids Symposium Series, Oxford, v.41, p.95-98, 1999.

HERMOSA, M.R.; GRONDONA, I.; ITURRIAGA, E.A.; DIAZ-MINGUEZ, J.M.; CASTRO, C.; MONTE, E.; GARCIA-ACHA, I. Molecular characterization and identification of biocontrol isolates of Trichoderma spp. Applied Environmental Microbiology, Washington, v.66, n.5, p.1890-1898, 2000.

HILLIS, D.M.; DIXON, M.T. Ribosomal DNA: molecular evolution and phylogenetic inference.
Quartely Review of Biology, Ithaca, v.66, n.4, p.411453, 1991.

KINDERMANN, J.; EL-AYOUTI, Y.; SAMUELS, G.J. Phylogeny of the genus Trichoderma based on sequence analysis of the Internal Transcribed Spacer Region 1 of the rDNA cluster. Fungal genetics and Biology, Amsterdam, v.24, n.3, p.298-309, 1998.

KISTLER, H.C.; BOSLAND, P.W.; BENNY, U.; LEONG, S.; WILLIAMS, P.H. Relatedness of strains of Fusarium oxysporum from crucifers measured by examination of mitochondrial and ribosomal DNA. Phytopathology, Cornell, v.77, n.9, p.1289-1293, 1987.

KURAMAE, E.E.; SOUZA, N.L. Variabilidade genética entre formae speciales de Fusarium oxysporum e raças 1 e 2 de $F$. oxysporum f. sp. lycopersici através de RAPD e sequências de regiões ITS e rDNA. Acta Scientiarum, Maringá, v.24, n.5, p.1481-1485, 2002.

LASERGENE. User's guide: a manual for the Lasergene System: biocomputing software for windows. Madson, 1994. 253p.

MANSO, S.B.G.; TENENTE, R.C.V. Nematóides (Heterodera glycines Ichinohe) formador do cisto da soja. Brasília: Embrapa, 1984. 5p. (Comunicado Técnico).

MARQUES, E.K. Diagnóstico genético molecular. Canoas: ULBRA, 2003. 370p.

MARQUES, E.K.; IKUTA, N.; LUNGE, V.R.; FONSECA, A.S.K. Diagnóstico molecular e biotecnologia. In: SERAFINI, L.A.; BARROS, N.M. de; AZEVEDO, J.L. de.

Biotecnologia: avanços na agricultura e na agroindústria. Caxias do Sul: EDUCS, 2002. p.101-129.

MELO, I.S. de. Trichoderma e Gliocladium como bioprotetores de plantas. Revisão Anual de Patologia de Plantas, Passo Fundo, v.4, p.261-295, 1996.

MENEZES, J.P. Caracterizacão populacional e molecular, e selecão de Trichoderma spp. para biocontrole de Fusarium sp. em crisântemo. 2007. 111p. Tese (Doutorado em Agronomia)-Universidade Federal de Santa Maria, Santa Maria, 2007.

PERES, E.; MELO, I.S. Variabilidade entre isolados de Trichoderma harzianum: I., aspectos citológicos. Scientia Agrícola, Piracicaba, v.52, n.1, p.56-59, 1995. 
POLETTO, I.; MUNIZ, M.F.B.; CECONI, D.E.; SANTIN, D.; WEBER, M.N.D.; BLUME, E. Zoneamento e identificação de Fusarium spp. causadores de podridão de raízes em plantios de erva-mate (Ilex paraguariensis a. St.-Hil.) na região do Vale do Taquarí - RS. Ciência Florestal, Santa Maria, v.16, n.1, p.1-10, 2006.

RIFAI, M. A revision of the genus Trichoderma. Mycological Papers, London, n.116, p.1-116, 1969.

SCHLOTTERER, C.; HAUSER, M.T.; HUESLER, A.;

TAUTZ, D. Comparative evolutionary analysis of rDNA ITS regions in Drosophila. Molecular Biology and Evolution, Oxford, v.11, n.3, p.513-522, 1994.

TAMURA, K.; KUMAR, S.; NEI, M. Mega: integrated software for molecular evolutionary genetics analysis and sequence alignment. Briefings in Bioinformatics, Baltimore, v.5, p.150-163, 2006.

VENTURA, J.A. Taxonomia de Fusarium e seus segregados: I., história, meios e procedimentos de cultivo. Revisão Anual de Patologia de Plantas, Passo Fundo, v.7, p.271-297, 1999.

WHITE, T.J.; BRUNS, T.; LEE, S.; TAYLOR, J. Amplification and direct sequencing of fungal ribosomal RNA genes for phylogenetics. In: INNIS, M.A.; GELFAND, D.H.; SHINSKY, J.J.; WHITE, T.J.PCR Protocols: a guide to methods and applications. New York: Academic, 1990. p.315-322.

WINDELS, C.E. Current status of Fusarium taxonomy. Phytopathology, Cornell, v.81, n.9, p.1048-1051, 1991. 